\title{
Smart Grid Technology and Its Possible Applications to the Nigeria 330 kV Power System
}

\author{
Oshevire Patrick $^{1}$, Oladimeji Tolulolope ${ }^{1}$, Onohaebi Sunny ${ }^{2}$ \\ ${ }^{1}$ Department of Electrical-Electronic-Engineering, College of Engineering, Afe Babalola University, Ado-Ekiti, Nigeria; ${ }^{2}$ Depart- \\ ment of Electrical-Electronic-Engineering, Faculty of Engineering, University of Benin, Benin City, Nigeria. \\ Email: ask4pat2001@yahoo.com,sunebi@yahoo.com, tolulopett@yahoo.com
}

Received May $2^{\text {nd }}, 2013$; revised June $29^{\text {th }}, 2013$; accepted July $7^{\text {th }}, 2013$

Copyright (C) 2013 Oshevire Patrick et al. This is an open access article distributed under the Creative Commons Attribution License, which permits unrestricted use, distribution, and reproduction in any medium, provided the original work is properly cited.

\begin{abstract}
It is a known fact that the epileptic power situation in Nigeria has become a recurring decimal. In the light of this stark reality of a country like Nigeria which is constantly plunged into pitch darkness all year round, it has become expedient for a sustainable and urgent remedy to be sought if our country will ever think of rubbing shoulders with the economies of the world. We find ourselves in this pathetic scenario that it has given rise to this paper which tends to review possible ways and means of redressing the ugly trend. This paper examines the prospects and possible applications of Smart Grid Technology (SGT) to the Nigeria Power System. Nigeria Power System consists of 28 buses, 32 Transmission lines and 10 generating stations, with a view to reduce the high active and reactive transmission losses. The study shows that smart grid system will make the present network more efficient and reliable by connecting different sources of distributed generators into the existing grid. Basic requirements necessary for the application of SGT using the Nigeria Power System as a case study were discussed.
\end{abstract}

Keywords: Smart Grid Technology (SGT); Nigeria Power System; Distributed Generators; Losses

\section{Introduction}

Smart grid is the term generally used to describe the integration of the elements connected to the electrical grid with an information infrastructure to offer numerous benefits for both the providers and consumers of electricity. It is an intelligent future electricity system that connects all supply, grid, and demand elements through an intelligent communication system [1]. It is an electrical power distribution network that includes two-way, digital communications between suppliers \& consumers (Department of Energy, USA).

Smart Grid Network is an intelligent, managed, controlled and ultimately self-healing electric distribution network capable of closely matching supply with demand while improving efficiency and reliability. Sensors and control devices on the grid, combined with integrated highspeed communications and advanced analytic software, provide utilities with actionable intelligence reports and information. Such tools make the electric utility more efficient and reliable, and in turn reduce the need for coal burning power plants that generate high levels of greenhouse gases. A Smart Electric Grid can identify where electricity is lost or where the system is not in balance or optimized. Such optimization can save $3 \%$ or more of overall electric demand without requiring any change in consumer behavior [2].

A common element to most definitions is the application of digital processing and communications to the power grid, making data flow and information management central to the smart grid.

Figure 1 shows a pictorial view of the proposed Smart Grid structure, from Generation to the Consumers.

\section{Overview of Smart Grid System Domain}

\subsection{Generation}

The smart grid can be applied to all areas of the power system involving generation, transmission, distribution and consumption.

Traditionally, the grid has been a centralized system with one way electron flows from the generator, along transmission wires, to distribution wires then to end customers.

One component of the smart grid allows for both movement and measurement in both directions, allowing 


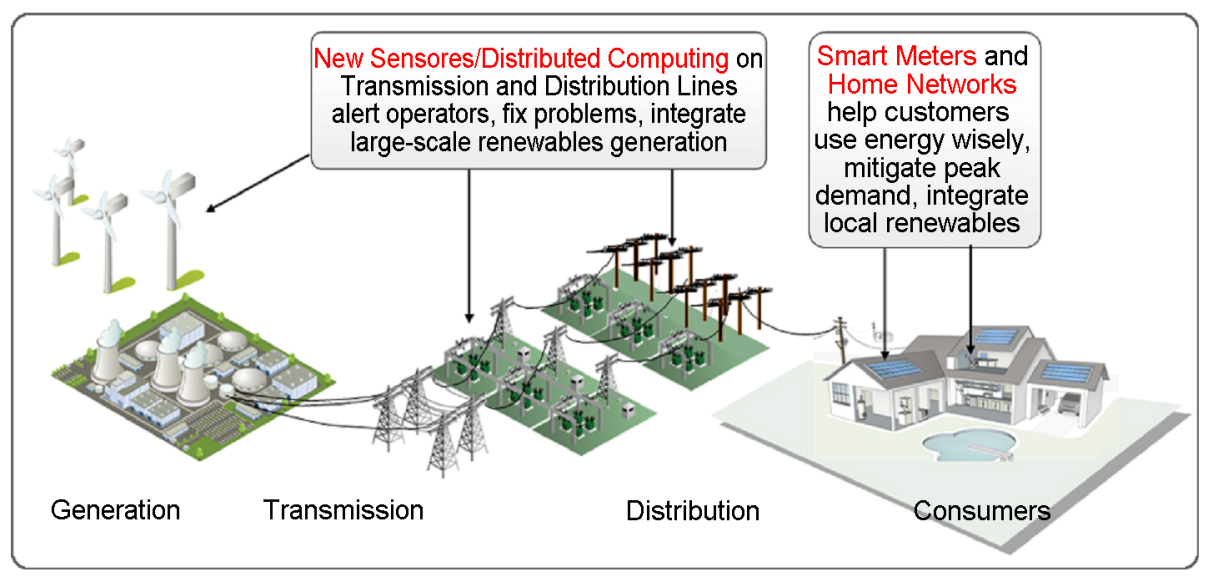

Figure 1. A concept of smart grid [3].

small localized generators to push their unused locally generated power back to the grid and also to get accurately paid for it. The wind and the sun, however, generate energy according to their own schedule, not the needs of the system. The smart grid is meant to manage intermittency of renewable generation through advanced and localized monitoring, dispatch and storage [2]. Figure 2 shows a proposed generating station of a proposed smart grid using shape.

\subsection{Transmission}

In a conventional grid, transmission is the bulk transfer of electrical power from generation sources to distribution through multiple substations. An electrical substation uses transformers to change voltage from high to low or the reverse across the electric supply chain and it contains switching, protection and control equipment.

In a smart grid system, a transmission network is typically operated by a Regional Transmission Operator or Independent System Operator (RTO/ISO) whose primary responsibility is to maintain stability on the electric grid by balancing generation (supply) with load (demand) across the transmission network.

Examples of actors in the smart grid transmission domain include remote terminal units, substation meters, protection relays, power quality monitors, phasor measurement units (sensors), sag monitors, fault recorders, and substation user interfaces.

The transmission domain will also contain distributed energy resources such as electrical storage or peaking generation units $[3,4]$.

Figure 3 shows a proposed transmission domain of a proposed smart grid using shape.

\subsection{Distribution}

The Distribution domain is the electrical interconnection between the Transmission domain, the Customer domain and the metering points for consumption, distributed

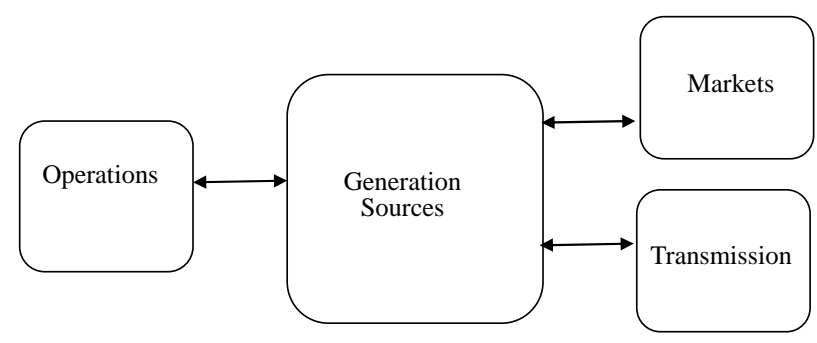

Figure 2. Smart generating station [4].

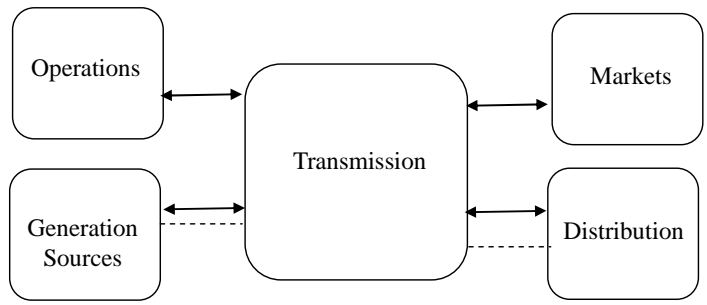

$\longleftrightarrow$ External Communication Interface

Electrical Interface

Figure 3. Overview of the transmission domain in a smart grid [4].

storage and distributed generation.

The reliability of the distribution system varies depending on its structure, the types of actors that are deployed, and the degree to which they communicate with each other and with the actors in other domains. The primary installed sensor base in this domain is the customer with a telephone, whose call initiates the dispatch of a field crew to restore power.

In the smart grid, the Distribution domain will communicate more closely with the Operations domain in real-time to manage the power flows associated with a more dynamic Markets domain and other environmental and security-based factors [2]. Figure 4 shows a proposed Distribution domain of a proposed Smart grid using shape. 


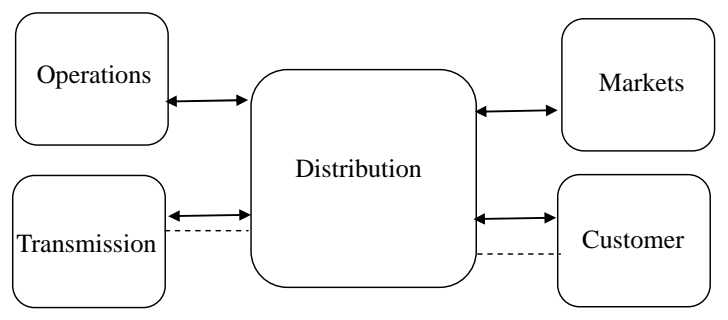

$\longleftrightarrow$ External Communication Interface

Electrical Interface

Figure 4. Distribution domain diagram [4].

\section{Overview of Nigeria Power System}

\subsection{Generation}

The total installed capacity of the currently generating plants in Nigeria is $7876 \mathrm{MW}$, but the available Capacity is less than $4000 \mathrm{MW}$ as at September 2011 [5]. Seven of the fourteen generation stations are over 20 years old and the average daily power generation is below $2700 \mathrm{MW}$, which is far below the peak load forecast of 8900 MW for the currently existing infrastructure.

Through the planned generation capacity projects for a brighter future, the current status of power generation in Nigeria presents challenges, such as inadequate generation availability, inadequate delayed maintenance of facilities, insufficient funding of power stations, obsolete equipment, tools, safety facilities and operational vehicles, obsolete communication equipment, lack of exploration to tap all sources of energy from the available resources and low staff morale [6].

\subsection{Transmission}

The current transmission system in Nigeria comprises $5523.8 \mathrm{~km}$ of $330 \mathrm{kV}, 6801.49 \mathrm{~km}$ of $132 \mathrm{kV}$, 32No. 330/132 kV Substations with total installed transformation capacity of 7688 MVA.

105No. 132/33/11 kV Substations with total installed transformation capacity of 9130 MVA. The average available capacity on $330 / 132 \mathrm{kV}$ is 7364 MVA and 8448 MVA on $132 / 33 \mathrm{kV}$. [7]

The Nigeria $330 \mathrm{KV}$ transmission grid is characterized by high power losses due to the very long transmission lines. Some of these lines include Benin-Ikeja West (280 km), Oshogbo-Benin (251 km), Oshogbo-Jebba (249 km), Jebba-Shiroro (244 km), BirninKebbiKainji (310 km), Jos-Gombe (265 km) and KadunaKano $(230 \mathrm{~km})$.

Power losses result in lower power availability to the consumers, leading to inadequate power to operate the appliances. Thus, the high efficiency of the power system is determined by its low power losses. Increased power demand pushes the power transmission and distribution networks to their upper limits and beyond, resulting to shortening of the life span of the network or total collapse [8].

The transmission system in Nigeria system does not cover every part of the country. It currently has the capacity to transmit a maximum of about $4000 \mathrm{MW}$ and it is technically weak, thus very sensitive to major disturbances. Major problems associated with transmission systems include poor funding by the Federal Government, it is yet to cover many parts of the country, it's current maximum electricity wheeling capacity is $4000 \mathrm{MW}$ which is awfully below the required national needs, some sections of the grid are outdated with inadequate redundancies as opposed to the required mesh arrangement, regular vandalization of the lines, associated with low level of surveillance and security on all electrical infrastructure, technologies used generally deliver very poor voltage stability and profiles, there is a high prevalence of inadequate working tools and vehicles for operating and maintaining the network, there is a serious lack of required modern technologies for communication and monitoring, transformers deployed are overloaded in most service areas, inadequate of spare parts for urgent maintenance, poor technical staff recruitment, capacity building and training programme [6].

\subsection{Distribution \& Marketing}

In most locations in Nigeria, the distribution network is poor, the voltage profile is poor and the billing is inaccurate. As the department, which inter-faces with the public, the need to ensure adequate network coverage and provision of quality power supply in addition to efficient marketing and customer service delivery cannot be over emphasized. Some challenges identified are, weak and inadequate network coverage, overloaded transformers and bad feeder pillars, substandard distribution lines, poor billing system, unwholesome practices by staff and very poor customer relations, inadequate logistic facilities such as tools working vehicles, poor and obsolete communication equipment, low staff morale and lack of regular training, insufficient funds for maintenance activities. [6]

\section{Basic Requirement for Smart Grid Technology}

Some of the technologies are actively being deployed and are considered mature in both their development and application, while others require further development and demonstration. However, not all technology areas need to be installed to increase the "smartness" of the grid [9].

Table 1, summarizes the technology involved in a proposed smart grid while Table 2, provides a concise summary of some of the differences between the current grid in Nigeria and proposed smart grid. 
Table 1. Proposed smart grid technologies [9].

\begin{tabular}{|c|c|c|}
\hline Technology Area & Hard Ware & Systems and Software \\
\hline $\begin{array}{l}\text { Wide-area monitoring } \\
\text { and control }\end{array}$ & $\begin{array}{l}\text { Phasor measurement units (PMU) and other sensor } \\
\text { equipment like accelerometers, infrared sensors, } \\
\text { strain guage and magnetic sensors. }\end{array}$ & $\begin{array}{l}\text { Supervisory control and data } \\
\text { acquisition (SCADA), wide-area monitoring systems } \\
\text { (WAMS), Grid lab view user interface. }\end{array}$ \\
\hline $\begin{array}{l}\text { Information } \\
\text { and communication } \\
\text { technology integration }\end{array}$ & $\begin{array}{l}\text { Communication equipment (Power line carrier, } \\
\text { WIMAX, LTE, RF mesh network, cellular), routers, } \\
\text { relays, switches, gateway, computers (servers) }\end{array}$ & $\begin{array}{l}\text { Enterprise resource planning software (ERP), } \\
\text { customer information system (CIS) }\end{array}$ \\
\hline $\begin{array}{l}\text { Renewable and distributed } \\
\text { generation integration }\end{array}$ & $\begin{array}{l}\text { Power conditioning equipment for bulk power and } \\
\text { grid support, communication and control hardware } \\
\text { for generation and enabling storage technology }\end{array}$ & $\begin{array}{l}\text { Energy management system (EMS),distribution } \\
\text { management system (DMS), SCADA, geographic } \\
\text { Information system (GIS) }\end{array}$ \\
\hline Transmission enhancement & $\begin{array}{l}\text { Superconductors, Flexible AC Transmission } \\
\text { Systems(FACTS), High Voltage Direct Current- } \\
\text { Voltage Sourced Converter (HVDC-VSC), Sensors } \\
\text { and Unified Power Flow Controller (UPFC) for } \\
\text { voltage magnitude control, active and reactive } \\
\text { power flow control. }\end{array}$ & $\begin{array}{l}\text { Network stability analysis, automatic recovery } \\
\text { systems }\end{array}$ \\
\hline $\begin{array}{l}\text { Distribution grid } \\
\text { management }\end{array}$ & $\begin{array}{l}\text { Automated re-closers, switches and capacitors, } \\
\text { remote controlled distributed generation and storage, } \\
\text { transformer sensors, wire and cable sensors }\end{array}$ & $\begin{array}{l}\text { Geographic information system (GIS), distribution } \\
\text { management system (DMS), outage management } \\
\text { system (OMS), workforce management system } \\
\text { (WMS) }\end{array}$ \\
\hline $\begin{array}{l}\text { Advanced metering } \\
\text { infrastructure }\end{array}$ & Smart meter, in-home displays, servers, relays & Meter data management system (MDMS) \\
\hline
\end{tabular}

Table 2. Difference between Nigeria network and proposed smart grid (compiled by Author).

\begin{tabular}{|c|c|c|}
\hline Criteria & Nigeria Current Power Grid System & Proposed Smart Grid \\
\hline Communications & None or one-way; typically not real-time & Two-way, real-time \\
\hline Customer interaction & Limited & Extensive \\
\hline Metering & Mainly electromechanical & Digital (enabling real-time pricing and net metering) \\
\hline Operation and maintenance & Manual equipment checks. & $\begin{array}{l}\text { Remote monitoring, predictive, time-based } \\
\text { maintenance }\end{array}$ \\
\hline Power flow control & Limited & Comprehensive, automated \\
\hline Reliability & $\begin{array}{l}\text { Prone to failures and cascading } \\
\text { outages; essentially reactive }\end{array}$ & $\begin{array}{c}\text { Automated, pro-active protection; prevents outages } \\
\text { before they start }\end{array}$ \\
\hline $\begin{array}{l}\text { Restoration following } \\
\text { disturbance }\end{array}$ & Manual & Self-healing \\
\hline System topology & Radial; generally one-way power flow & $\begin{array}{l}\text { Closed network; multiple power } \\
\text { flow pathways }\end{array}$ \\
\hline $\begin{array}{l}\text { Transmission/Distribution line } \\
\text { losses }\end{array}$ & $\begin{array}{l}\text { Above ten percent }(10 \%) \text { loss of the total power in } \\
\text { the transmission/distribution lines. }\end{array}$ & $\begin{array}{l}\text { About two percent ( } 2 \%) \text { loss of the total power in the } \\
\text { transmission/distribution lines. }\end{array}$ \\
\hline
\end{tabular}

\section{Requirements for Application of Smart Grid Technology in Nigeria Power System}

\subsection{Transmission Enhancement}

Equipment typically found in PHCN substations includes the following: switch gears, high rupturing capacity fuses (HRC), air-cored ring shielded reactors, lightening arresters, circuit breakers, power transformers, isolators, and bus bars, among other items, while the network components include power lines, cables, circuit breakers, switches, transformers, large size conductors, steel lattice towers, steel tubular poles, wooden poles, earthing

\section{equipment.}

In Nigerian transmission power system, it will become important to fully utilize the existing transmission facilities instead of building new power plants and transmission lines that are costly to implement and involve long construction times. Flexible Alternating Current Transmission Systems (FACTS) controllers can be introduced in power systems to solve the above problems. FACTS make it possible to control the voltage magnitude of a bus, active and reactive power flows through transmission line of a power system.

Line sensors can also be introduced to monitor real time situations of the Network. 


\subsection{Renewable, Distributed Generation Integration and Micro Grid}

Nigeria generates electricity through large centralized hydro plants scattered around the country and thermal plants also. Regardless of where power plants are located, their power must be brought from the plant to the users.

It lies within a high sunshine belt and thus has enormous solar energy potentials. The average of total solar radiation varies from about $3.5 \mathrm{kWhm}^{-2} \cdot \mathrm{day}^{-1}$ in the coastal latitudes to about $7 \mathrm{kWhm}^{-2} \cdot \mathrm{day}^{-1}$ along the semi arid areas, the country receives solar radiation at the level of about $19.8 \mathrm{MJm}^{-2} \cdot \mathrm{day}^{-1}$. Average sunshine hours are estimated at $6 \mathrm{hr}$ per day. Solar radiation is fairly well distributed.

Given an average solar radiation level of about 5.5 $\mathrm{kWhm}^{-2} \cdot \mathrm{day}^{-1}$, and the prevailing efficiencies of commercial solar-electric generators, then if solar collectors or modules were used to cover $1 \%$ of Nigeria's land area of $923,773 \mathrm{~km}^{2}$, it is possible to generate $1850 \times 103$ GWh of solar electricity per year, [10], in this vein, if solar electricity is developed in Nigeria it can be used for power supply to remote villages and locations not connected to the national grid. It may also be used to generate power for feeding into the national grid.

Wind-Nigeria has significant onshore and offshore exploitable wind energy reserves, but so far this remains an under-explored sector. Wind, which is an effect from the uneven heating of the earth's surface by the sun and its resultant pressure inequalities, is available at annual average speeds of about $2.0 \mathrm{~m} / \mathrm{s}$ at the coastal region and $4.0 \mathrm{~m} / \mathrm{s}$ at the far northern region of the country [10].

Wind energy is considered a viable solution to the energy challenges of Nigeria especially in the rural areas of the country and to the restrictions posed by the rising cost of conventional or traditional energy.

Implementing distributed generation can be as simple as installing a small generator to provide back up or it can be a complex system, highly integrated with the electricity grid and consisting of electricity generation, energy storage and power management systems. Distributed generation can support and strengthen the central station model of electricity generation, transmission and distribution. While the central generating plant continues to provide most of the power to the grid, the distributed resources can meet the peak demands of local distribution feeder lines or major customers.

Microgrids can be utilized as the framework of system that can reduce the negative effects of power fluctuation on existing power systems, simultaneously pursuing the coexistence of environment and supply, and existing power system and distributed power generation. They can also be considered to be a flexible load. It keeps the power demand and supply balance by connecting to the external power system for maintenance of frequency and voltage. Microgrid operators buy power through tie-line from the utility company when power in the microgrids is deficient, and sell power when the power generated is in excess [11].

\subsection{Advanced Metering Infrastructure}

Presently electromechanical meters are used by consumers of Power Holding Company of Nigeria, they have mechanical parts that spin as electricity is consumed in the premises, and they show usage readout on small dials that a utility meter reader reads while on the property of your home.

Smart meters, otherwise referred to as Advanced Metering Infrastructure (AMI) or two-way meters, are electric meters which utilize two-way communications between the meter and the utility company and enable twoway power flows to consumers. This technology enables users to monitor their consumption patterns in real-time and enables features which include time stamping of meter data, outage reporting, communication into the customer premise and on-request reads. It also enables the consumer to supply power back to the grid from solar panels or other local renewable sources and enables load management by responding to fluctuations in demand. [12].

\subsection{Wide Area Monitoring, Control and Storage Devices}

The use of sensors, phasor measurement units (PMU), accelerometers, infrared sensors, strain guage and magnetic sensors, if mounted in Nigerian System can be monitored by intelligent systems throughout the network is intended to allow the system to automatically adapt and respond to changing conditions. It is expected that distribution devices will become intelligent remote agents on communication networks providing data collected through sensors back to operations control centers. With current technology it is difficult to monitor power flows throughout the distribution grid as measurements are typically only available at the distribution substations. Sensors located throughout the network along with smart metering will be able to collect this information.

Energy storage technologies such as Hybrid Air Conditioning systems can convert electrical energy to thermal energy and store it. This is more economical than storing electricity in batteries. Such storage capabilities will be needed to grow the alternative energy sources, where unstable power flow from renewable energy plants such as wind and solar farms can be stored and better controlled. It can also supply power to the grid when it goes into island mode [11].

Modern means of data monitoring and analysis in a Smart Grid Power Network. 
Supervisory Control and Data Acquisition Systems (SCADA) has been introduced into Nigeria Power System by PHCN for data collection and monitoring of the generating station. Other softwares that were also studied include:

Distribution Management System (DMS) power flow monitoring software that can be used to run different grid operation scenarios pulling data from a centralized database that is always updated and synchronized with the network. This database has all the information needed to simulate situations such as three-phase unbalanced power flow, or perform contingency and short circuit analysis.

Visualizing Energy Resources Dynamically on Earth (VERDE) similar to Google Earth, VERDE simulation allows grid modeling with geographical information using real-time sensor data and weather information. This will enable the operator to visualize the condition of the grid at different levels, switching the view of the grid display from national to regional or even street level, all within a few seconds.

GridLAB-D is a flexible simulation environment that can be integrated with a variety of third-party data management and analysis tools.

The GridLAB-D system includes modules to support implementation of the following system simulation functions; power flow controls, including distributed generation and storage, end-use appliance technologies, equipment, and controls, consumer behavior including daily, weekly, and seasonal demand profiles, price response, and contract choice, energy operations, such as distribution automation, load-shedding programs, and emergency operations, business operations, such as retail rate, billing, and market-based incentive programs.

Advanced Power Quality software, such as labview, allows detailed power quality data to be examined rapidly and easily, making best use of human pattern recognition and analysis skills.

Oracle Utilities Meter Data Management, smart meters may be monitored by this software, essentially processing meter data. Other oracle software include: Oracle Utilities Customer Care and Billing, Oracle Utilities Load Analysis, Oracle Utilities Work and Asset Management, Oracle Utilities Meter Data Management, Oracle Database $[13,14]$.

\section{Benefits Derivables of a Smart Grid}

1) The grid will heal itself. The modernized grid will perform continuous self assessments to detect, analyze, respond to and as needed, restore grid components or network sections. It will handle problems too large or too fast moving for human intervention. Acting as the grid's "immune system", self healing will help maintain grid reliability, security, affordability, power quality and effi- ciency;

2) It will motivate consumers to be an active grid participant and will include them in grid operations. In the modernized grid, well-informed consumers will modify consumption based on the balancing of their demands and the electric system's capability to meet those demands. Demand for new cost-saving and energy-saving products will benefit both the consumer and the power system.

Consumers help balance supply and demand, and ensure reliability by modifying the way they use and purchase electricity. These modifications come as a result of consumers having choices that motivate different purchasing patterns and behaviour. These choices involve new technologies, new information about their electricity use, and new forms of electricity pricing and incentives.

3) The modern grid will resist attack. Security requires a system-wide solution that will reduce physical and cyber vulnerabilities and recovers rapidly from disruptions. Both its design and its operation will discourage attacks, minimize their consequences and speed service restoration.

Resiliency refers to the ability of a system to react to unexpected events by isolating problematic elements while the rest of the system is restored to normal operation. These self-healing actions result in reduced interruption of service to consumers and help service providers better manage the delivery infrastructure.

4) The modern grid will provide the level of power quality desired by the users.

New power quality standards will balance load sensitivity with delivered power quality at a reasonable price. The modernized grid will supply varying grades of power quality at different pricing levels.

Not all commercial enterprises, and certainly not all residential customers, need the same quality of power. A smart grid supplies varying grades (and prices) of power. The cost of premium power-quality features can be included in the electrical service contract. Advanced control methods monitor essential components, enabling rapid diagnosis and solutions to events that impact power quality, such as lightning, switching surges, line faults and harmonic sources.

5) The modern grid will accommodate all generation and storage options. It will seamlessly integrate many types of electrical generation and storage systems with a simplified interconnection process analogous to "plugand-play” technology of the retail computer industry.

A smart grid accommodates not only large, centralised power plants, but also the growing array of customersited distributed energy resources. Integration of these resources-including renewables, small-scale combined heat and power, and energy storage-will increase rapidly all along the value chain, from suppliers to market- 
ers to customers.

6) The modern grid will enable markets to flourish. Open-access markets, expose and shed inefficiencies. The modern grid will enable more market participation through increased transmission paths, aggregated demand response initiatives and the placement of energy resources including storage within a more reliable distribution system that is closer to the consumer.

Correctly designed and operated markets efficiently create an opportunity for consumers to choose among competing services. Some of the independent grid variables that must be explicitly managed are energy, capacity, location, time, rate of change and quality. Markets can play a major role in the management of these variables. Regulators, owners/operators and consumers need the flexibility to modify the rules of business to suit operating and market conditions.

7) Optimises asset utilisation and operating efficiency-A smart grid applies the latest technologies to optimise the use of its assets. For example, optimised capacity can be attainable with dynamic ratings, which allow assets to be used at greater loads by continuously sensing and rating their capacities. Maintenance efficiency can be optimised with condition-based maintenance, which signals the need for equipment maintenance at precisely the right time. System-control devices can be adjusted to reduce losses and eliminate congestion. Operating efficiency increases when selecting the least-cost energy-delivery system available through these types of systemcontrol devices [9,14].

\section{Conclusions}

We have seen that the present Nigerian grid is facing the problem of poorly maintained long transmission lines, inadequate communication facilities and insufficiency in power generation.

We have proposed a method of supply reliability evaluation for microgrids, including renewable energy sources, installation of electric energy storage systems etc.

Renewable energy is considered a viable solution to the energy challenges of Nigeria especially in the rural areas of the country and to the restrictions posed by the rising cost of conventional or traditional energy.

The goal of a smart grid, as it relates to consumers, is to manage energy use more efficiently, save money on electricity, and provide technology and processes that are integrated into the appliances and devices consumers use in their everyday lives, all without causing significant disruption. A successful smart grid will allow consumers to receive valuable and understandable information that enables them to make intelligent and informed choices about how they use energy, all while minimizing consumer cost and out-of-pocket expenses that could arise with the implementation of the smart grid. The willingness of consumers in Nigeria to accept and participate in the smart grid could be severely impaired if the cost outweighs the benefits.

\section{REFERENCES}

[1] P. Venkat and M. Saadat, "Smart Grid-Leveraging Intelligent Communicationsto Transform the Power Infrastructure,” Cisco Systems, Inc., 2009.

[2] D. Von Dollen, "Report to NIST on the Smart Grid Interoperability Standards Roadmap,” 2009.

[3] J. Kuriakose, "Distributed Generation, Smart Grid and Micro Grid,” International Conference for Alternative Technology, 2008.

[4] "Smart Grid, Future Grid-A Basic Information Report on Smart Grid, Joint US-China Cooperation on Clean Energy (JUCCCE),” 2007.

[5] Phcn, "Report on Generation Profile of the Country," 2011.

[6] A. S. Sambo, B. Garba, I. H. Zarma and M. M. Gaji"Electricity Generation and the Present Challenges in the Nigerian Power Sector,” Energy Resources Review, Vol. 4, No. 3, 2003, pp. 7-10.

[7] H. S. Labo (C.E.O TCN), “A Paper Presentation Current Status and Future Outlook of The Transmission Network," Investor's Forum for the Privatization of PHCN Successor Companies, 2010.

[8] O. O. Sunday and O. O. Friday, "Empirical Modelling of Power Losses as a Function of Line Loadings and Lengths in the Nigerian $330 \mathrm{kV}$ Transmission lines," International Journal of Academic Research, Vol. 2, No. 3. 2010.

[9] “Technology Road Map on Smart Grids,” International Energy Agency (IEA), 2011.

[10] S. Abubakar, "Strategic Developments in Renewable Energy in Nigeria,” International Association of Energy Economics, 2005.

[11] Integration of Demand-Side Management, Distributed Generation, "Renewable Energy Sources and Energy Storages,” International Energy Agency Demand-Side Management Programme (ieadsm), Finland, 2009.

[12] "Gurlin Singh Lamba-Smart Grid and Its Development Prospects in the Asia-Pacific Region,” Journal of Emerging Trends in Computing and Information Sciences, Vol. 2, No. 1, 2011.

[13] “Oracle White Paper: Smart Grids-Strategic Planning and Development,” 2009.

[14] Smart Grid by PDHengineer.com, Course no E-5006. http://www.pdhengineer.com/pages/E-5006.htm 